JIOM Nepal, Volume 41, Number 2, August 2019, page 70-72

\title{
Batwing Technique in Large Volume Excision of Breast Lesions: Case Report
}

\author{
'Suman Khanal, 'Yogendra P Singh, ${ }^{2}$ Rashmi Sharma \\ ${ }^{1}$ Breast and Thyroid Unit, Department of GI and General Surgery, Maharajgunj Medical Campus „, Tribhuvan University \\ Teaching Hospital, Maharajgunj, Kathmandu, Nepal \\ 'Department of Dermatology, Maharajgunj Medical Campus," Tribhuvan University Teaching Hospital, Maharajgunj, \\ Kathmandu, Nepal
}

\section{Corresponding author:}

Suman Khanal, MBBS, MS

Breast and Thyroid Unit, Department of GI and General Surgery, Maharajgunj Medical Campus „, Tribhuvan University Teaching Hospital, Maharajgunj, Kathmandu, Nepal

Email:sumandoc@iom.edu.np

Submitted: Jun 6, 2019

Accepted : Jul 31, 2019

\begin{abstract}
Oncoplastic surgical techniques are seeing widespread use for excision of large volume breast lesions. Batwing technique is one of the volume displacement techniques that can be used to manage lesions in central quadrant of the breast. Such techniques are still underused in Nepal. Here we present three cases with large volume benign breast lesions managed with simple, easy-to-learn technique of Batwing oncoplasty.
\end{abstract}

Keywords: Batwing, fibroadenoma, oncoplasty, phyllodes

\section{INTRODUCTION}

$\mathrm{O}$ ncoplastic procedures in breast have addressed the shortcomings of breastconserving surgery to allow for generous resection of tumors of breast without compromising the cosmetic outcome and oncological principles. ${ }^{1}$ Initially developed for carcinomas of breast, these techniques can also be applied to the management of giant fibroadenomas and phyllodes tumors. ${ }^{2}$ Volume loss of more than $20 \%$ in BCS (breast conserving surgery) are likely to result in cosmetic failure. ${ }^{3,4}$ These are remedied to an extent with oncoplastic procedures. Larger resections are better managed with volume replacement techniques of oncoplasty. In this report, we show how 'Batwing' technique can also be used to manage large volume resection with good cosmetic outcome.

Batwing technique is a volume displacement technique of oncoplasty used for excision of breast malignancy located in upper aspect and central quadrant of breast within a few centimeters but not directly involving nipple-areolar complex (NAC) ${ }^{5,6}$ It consists of two semicircular parallel lines above NAC with two angled incisions to connect these two lines in a wing pattern. ${ }^{5,6}$ As the wing extends medially and laterally, it allows full thickness fibroglandular excision of larger lesions medial or lateral to NAC. The breast is reshaped with advancement of fibroglandular tissue and skin with absorbable sutures. In cases of ptosis of breasts, it also allows for pulling up of the nipple.

\section{CASE PRESENTATION}

First case was an 11 years-old premenarchal female with fast growing lump in right breast for one year. No history of trauma, nipple discharge or similar illness in family members. On examination, her breast was pendulous with nipple-areola complex (NAC) pointing down. The lump was in dependent position of breast measuring $11 \times 11 \mathrm{~cm}$. Axilla revealed no lymphadenopathy. Nipple was $26 \mathrm{~cm}$ from manubrium while on normal side was $18 \mathrm{~cm}$. Fine needle aspiration cytology (FNAC) was suggestive of fibroadenoma. She underwent batwing technique for excision of lump. As the NAC was larger, excess areola was de-epithelialized to make bilateral NAC symmetric. At two weeks follow up breast contour was well maintained with good cosmesis (Fig 1). Final histopathological examination (HPE) report confirmed FNAC findings.

Second case was a 29 years-old unmarried female with progressively increasing lump in left breast for four months. She attained menarche at 15 years of age. No other significant history. On examination, the breast was diffusely enlarged with $13 \times 15 \mathrm{~cm}$ firm mass in superior and retroareolar regions of breast. Mass was free from skin and underlying pectoralis. 

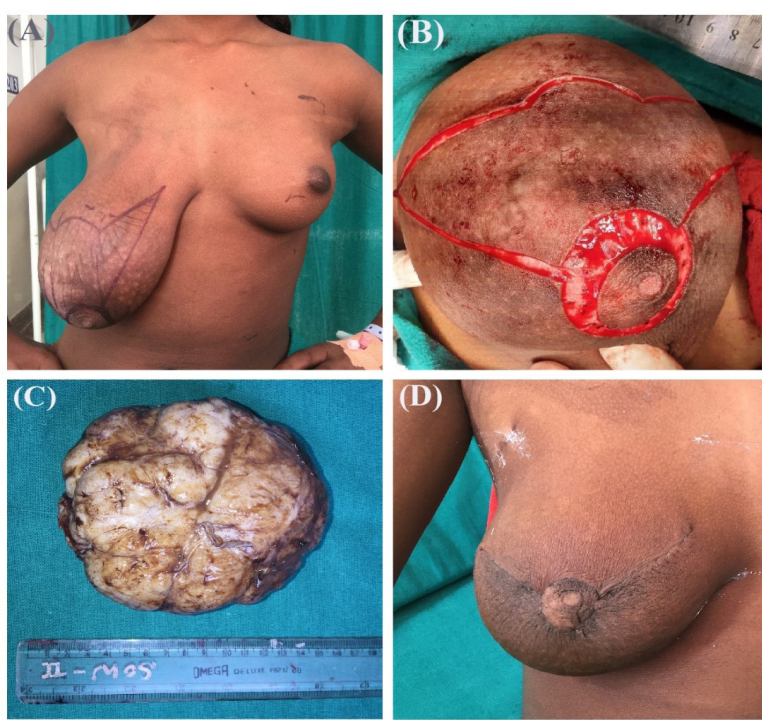

Figure 1. (A) Pendulous right breast with NAC pointing down (B) Incision, note the periareolar de-epithelialization to make NAC symmetric (C) Excised specimen (D) At 2 weeks well maintained contour with good cosmesis
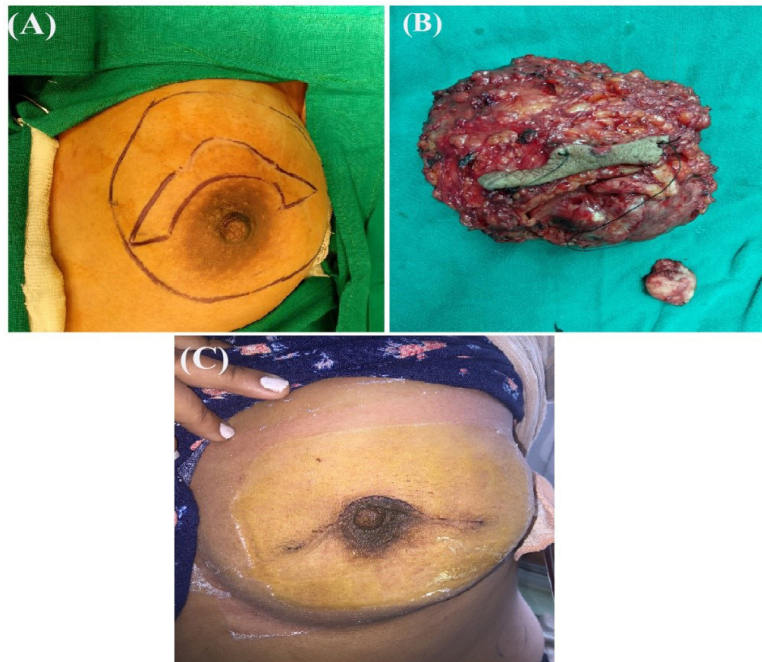

Figure 2. (A) Marking showing the tumor (B) Excised specimen, note the fibroadenoma adjacent to the mass (C) Maintained contour of breast at two weeks despite large volume excision

Trucut biopsy of mass revealed phyllodes tumor. The mass was excised with batwing oncoplastic technique. HPE of excised mass showed phyllodes tumor with adjacent separate distinct fibroadenoma (Fig 2). Breast contour was maintained at 2 weeks with good cosmetic outcome.

Third case was a 16 years-old unmarried female with progressively increasing painless lump in right breast for one year. She attained menarche at 15 years. Other history was unremarkable. On examination, right breast was tensely enlarged with $11 \times 14 \mathrm{~cm}$ firm mass in lateral and retroareolar regions with nipple retraction. Axilla was unremarkable. FNAC was suggestive of fibroadenoma which was coherent with final HPE report (Fig 3). Post-excision, breast contour was well maintained with NAC at same level.

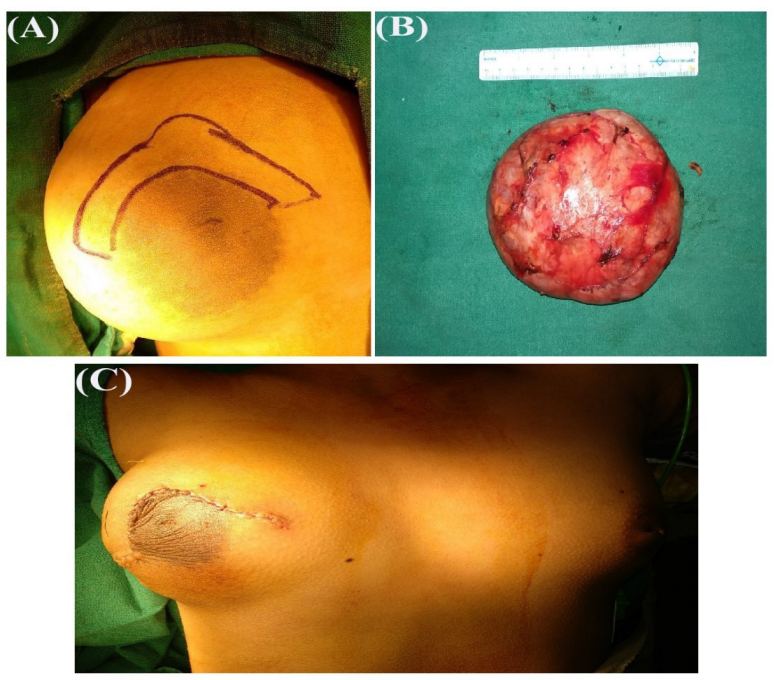

Figure 3. (A) Tensely enlarged breast (B) Excised specimen (C) Post-excision photograph showing maintained contour despite large volume excision

\section{DISCUSSION}

More than $20 \%$ breast volume excision leads to unacceptable cosmetic defect. ${ }^{3}$ Larger breast lesions can be managed by mastectomy, free flaps or oncoplastic techniques. ${ }^{7}$ Mastectomy leads to anxiety, depression, poor sexuality and self-esteem ${ }^{8}$ while free flaps are associated with longer operative time and more morbidity. Oncoplastic techniques which integrate cancer resection with plastic surgery techniques are free of these shortcomings. These techniques can be either volume displacement or replacement techniques. Volume replacement techniques are ideal for large breast volume excision. However, volume displacement technique like Batwing technique which is a level II OPS (oncoplastic surgery) ${ }^{4}$ procedure can even be applied in large volume excision. In our case, we removed upto $15 \mathrm{~cm}$ sized benign phyllodes tumor with good cosmetic outcome. Batwing mammoplasty has good patient satisfaction with low complications compared to Wise pattern mammoplasty. ${ }^{9}$ Though the first case might have benefited from Wise pattern mammoplasty, we sticked to Batwing due to younger age of the patient (less tissue damage)and comparable cosmetic outcome with lower complications. ${ }^{9}$ As it involves an incision that centers around nipple-areolar complex (NAC), in asymmetric large areola, excess areolar skin can be de-epithelialized as in the first case for better cosmesis. Though other oncoplastic techniques are used in management of benign breast lesions in literature, ${ }^{10,11}$ there is only a case report on use of Batwing in management of giant fibroadenoma ${ }^{12}$ which has reported good cosmetic outcome. Our study is unique in that we assessed Batwing technique in three patients with benign breast lesions.

Use of oncoplastic breast conserving surgeries is minimal in Nepal. Data from a prominent tertiary 
care cancer hospital in Nepal showed almost all (99\%) of surgeries in invasive breast cancer to be mastectomies. ${ }^{13}$ With increasing information and awareness, use of oncoplastic techniques may increase in future in Nepal.

\section{CONCLUSION}

Batwing volume displacement oncoplastic technique can be applied even for larger benign breast lesions with good early cosmetic outcome without compromising margins.

\section{CONFLICT OF INTEREST}

None declared.

\section{REFERENCES}

1. Macmillan RD, McCulley SJ. Oncoplastic Breast Surgery: What, When and for Whom? Curr Breast Cancer Rep. 2016;8:112-7.

2. FRCPEd(Hon) JMDBsMbcMFFrcse, Surg) MDBBsMbcMF, editors. Breast Surgery: A Companion to Specialist Surgical Practice. 6 edition. Edinburgh London New York: Elsevier; 2018. 304 p.

3. Bulstrode NW, Shrotria S. Prediction of cosmetic outcome following conservative breast surgery using breast volume measurements. Breast Edinb Scotl. 2001 Apr;10(2):124-6.

4. Clough KB, Kaufman GJ, Nos C, Buccimazza I, Sarfati IM. Improving breast cancer surgery: a classification and quadrant per quadrant atlas for oncoplastic surgery. Ann Surg Oncol. 2010 May;17(5):1375-91.

5. Anderson BO, Masetti R, Silverstein MJ. Oncoplastic approaches to partial mastectomy: an overview of volume-displacement techniques. Lancet Oncol. 2005 Mar;6(3):145-57.

6. Holmes DR, Schooler W, Smith R. Oncoplastic Approaches to Breast Conservation [Internet]. International Journal of Breast Cancer. 2011 [cited 2019 Jul 30]. Available from: https://www.hindawi.com/ journals/ijbc/2011/303879/

7. Piper M, Peled AW, Sbitany H. Oncoplastic breast surgery: current strategies. Gland Surg. 2015 Apr;4(2):154-63.

8. Margolis G, Goodman RL, Rubin A. Psychological effects of breast-conserving cancer treatment and mastectomy. Psychosomatics. 1990;31(1):33-9.

9. Hashem T, Farahat A. Batwing versus Wise pattern mammoplasty for upper pole breast tumours: a detailed comparison of cosmetic outcome. World J Surg Oncol [Internet]. 2017 Mar 14 [cited 2019 Mar 10];15. Available from: https://www.ncbi.nlm.nih.gov/pmc/articles/ PMC5351177/

10. Nour A, Gharieb F, Tashkandi M, Helmy T. Oncoplastic breast surgery for the management of giant and multiple benign breast lesions. Eur Surg. 2011 Oct 1;43(5):295301.

11. Ren J, Jin $L$, Leng $B$, Hu R, Jiang G. Surgical excision and oncoplastic breast surgery in 32 patients with benign phyllodes tumors. World J Surg Oncol. 2018 Jul 24;16(1):153.

12. Adding bit of esthetics with science modification of batwing mastopexy for breast conservation in a young patient with giant fibroadenoma breast. 2001 [cited 2019 Jul 30]; Available from: http://www.cancerjournal. net/preprintarticle. asp? $\mathrm{id}=244476$

13. BPKMCH Annual Report [Internet]. BP Koirala Memorial Cancer Hospital; 2016. Available from: http://bpkmch. org.np/images/BPKMCH_Annual_Report_2016_New.pdf 